\title{
Potential therapeutic targets and small molecular drugs for pediatric B-precursor acute lymphoblastic leukemia treatment based on microarray data
}

\author{
LIMEI KONG* ${ }^{*}$, XIAOWEI ZHANG* ${ }^{*}$ CHAO LI and LIPING ZHOU \\ Department of Pediatrics, The No. 6 People's Hospital of Jinan, Jinan, Shandong 250200, P.R. China
}

Received March 24, 2016; Accepted April 6, 2017

DOI: $10.3892 / \mathrm{ol} .2017 .6343$

\begin{abstract}
The current study investigated the molecular mechanisms underlying pediatric acute lymphoblastic leukemia (ALL) and screened for small molecular drugs as supplementary drugs to aid current therapy. Gene expression data of Gene Expression Omnibus (GEO) DataSet GSE42221, which consists of 7 primary human B-precursor samples and 4 control B-cell progenitor lymphoblast samples from patients with pediatric ALL, were downloaded from the public GEO database. Linear Models for Microarray Analysis package for R statistical software was used to identify differentially expressed genes (DEGs). Subsequently, biclustering analysis of DEGs was performed using pheatmap package for R. Functional enrichment analysis of DEGs was conducted using the Database for Annotation, Visualization and Integrated Discovery tool. Additionally, Search Tool for the Retrieval of Interacting Genes software was used to screen protein-protein interactions (PPIs) of the DEGs, and Connectivity Map database was employed to obtain small-molecule drugs that were significantly associated with DEGs. In total, 116 genes were identified as DEGs in pediatric ALL, including 56 downregulated and 60 upregulated genes. Functional enrichment analysis identified that upregulated DEGs, including marker of proliferation $\mathrm{Ki}-67$, cyclin $\mathrm{F}$ and nucleolar and spindle associated protein 1, were significantly enriched in mesenchymal cell differentiation and development processes, whilst downregulated DEGs, including bone marrow morphogenetic protein 2, semaphoring 3F and ephrin B1 were enriched in cell cycle process. Amongst the DEGs, 169 PPIs were identified.
\end{abstract}

Correspondence to: Dr Limei Kong or Dr Chao Li, Department of Pediatrics, The No. 6 People's Hospital of Jinan, 1920 Huiquan Road, Zhuangqiu, Jinan, Shandong 250200, P.R. China

E-mail: limeikkkk@163.com

E-mail: chaolichchhcdfs@126.com

*Contributed equally

Key words: pediatric acute lymphoblastic B-cell leukemia differentially expressed genes, functional enrichment, small-molecule drugs, interaction network
Notably, carbimazole and quinostatin were associated with DEGs. Additionally, a number of DEGs were targeted by the two drugs, including signal transducer and activator of transcription 3, nucleolar and spindle associated protein 1 and cell division cycle 20. Mesenchymal cell differentiation and development as well as cell cycle processes may be important for pediatric ALL. Quinostatin may be used as a potent supplementary drug for treating pediatric ALL.

\section{Introduction}

Acute lymphoblastic leukemia (ALL) is the most frequent hematologic malignancy in pediatric patients, and ALL develops due to a combination of genetic susceptibility and environmental exposure in fetal life and infancy (1). In the United States, the incidence rate (age-adjusted) was reported to be 4.9 per 100,000 children from 2007 to 2011 (2). Despite advancements in the management of pediatric ALL (B-cell and T-cell ALL), that have occurred, the incidence of the disease has exhibited an increasing trend (3). Post-transplant relapse remains the primary causative factor for treatment failure in $30 \%$ of patients with ALL (4). The disease relapse may be due to the chemotherapy resistance of leukemic cells following the initial treatment in the majority of these patients (5). Therefore, there is a requirement for novel effective therapeutic methods for the treatment of ALL.

Gene expression microarrays have emerged as an effective technique for identifying differentially expressed genes (DEGs) in a comprehensive approach. Previously, by using higher density oligonucleotide arrays, $~ 60 \%$ of the newly identified subtypes of discriminating genes were recognized as novel markers (6). Additionally, 54 genes were identified with distinguished resistance from sensitive ALL samples by comparing gene expression signatures of pediatric ALL tissue samples with or without high minimal residual disease (MRD) load (7). Additionally, a number of genes (protein products) were identified with increased expression levels (1.5-5.8 fold) in leukemic cells compared with control samples, including cluster of differentiation (CD)58 and human DNAJ protein (HDJ)-2 (8). These previous studies demonstrated that a large cohort of DEGs may be involved in the progression of ALL. Small molecule drugs have been identified as potential inhibitors of ALL, including imatinib, an Abelson tyrosine-protein kinase 1 inhibitor (9). Additionally, borrelidin was established 
as a potent agent inhibiting the cell proliferation in ALL cell lines via the induction of apoptosis and the regulation of G1 arrest (10). A previous study which established the Gene Expression Omnibus (GEO) DataSet gene expression array GSE42221 identified that the epigenetic and transcriptional regulation of zinc finger protein $(Z N F) 423$ was associated with B-cell differentiation in ALL $(11,12)$. However, the study focused on the causative role of the gene ZNF423 in ALL. Associated genes and their potential interactions, as well as small molecule drugs, were not considered in Harder et al (11).

Therefore, the current study re-analyzed the published expression profiles (11) and consequently identified DEGs in pediatric B-cell ALL. Additionally, functional enrichment analysis of DEGs was performed to investigate the dysregulated biological processes using the altered DEGs in the progression of the disease. In addition, the protein-protein interactions (PPIs) of the DEGs were screened and small molecular drugs associated with DEGs were analyzed using a number of bioinformatic methods. All these analyses were aimed to provide effective and novel therapeutic methods for the management of pediatric ALL.

\section{Materials and methods}

Data source. Gene expression data with the accession number of GSE42221, which was deposited by Harder et al (11) in the public National Center for Biotechnology Information GEO database, were downloaded. The dataset consisted of 7 primary human B-precursor samples (ALL samples) and 4 normal B-cell progenitor lymphoblast samples (control samples). For paired expression analysis (pairs, $n=4$ ), single primary leukemic cells and normal lymphoblasts were isolated from the same patients with pediatric ALL. The platform was GPL96 (HG-U133A) using the Affymetrix Human Genome U133A Array (Affymetrix Inc., Santa Clara, California, USA). The annotation of the probes from Affymetrix, including all information of Affymetrix ATH1 chip (25K array) was downloaded, as well as the primary files.

Data preprocessing and differential analysis. According to the annotation platform, a cohort of 22,283 probes was mapped to the corresponding genes. For each gene, the average value of multiple probes corresponding to a single gene was calculated to obtain gene expression value, which was then transformed into $\log 2$ ratio (13). Consequently, a total of 20,967 gene expression levels were obtained. DEGs were screened for each sample using Linear Models for Microarray Analysis (limma) package of R language (http://www.bioconductor .org/packages/release/bioc/html/limma.html) (14), in which the Benjamini and Hochberg method was applied for multiple testing correction (15). False discovery rate $<0.05$ and llog fold change $>1$ were set as the threshold values for DEG selection.

Clustering analysis of DEGs. Biclustering analysis of gene expression data directly identified whether the DEGs that were screened had specificity for the samples $(16,17)$. In the present study, pheatmap package of R language (http://cran.r-project .org/web/packages/pheatmap/index.html) was used for biclustering analysis of DEGs on the basis of Euclidean distance method (18).
Functional enrichment analysis of DEGs. Database for annotation, visualization, and integrated discovery (DAVID; http://david.abcc.ncifcrf.gov/) provided a set of data-mining tools that systematically combined functionally descriptive data with intuitive graphical displays (19). Therefore, DAVID tool was used for the Gene Ontology (GO) functional enrichment analysis of upregulated and downregulated DEGs, based on hypergeometric distribution algorithm. $\mathrm{P}<0.05$ was considered to indicate a statistically significant difference.

Interaction analysis of DEGs. To investigate the association between DEGs at the protein level, the Search Tool for the Retrieval of Interacting Genes (String, version 9.1; http://string-db.org/) (20) was used to screen the PPIs with the threshold of combined score $>0.4$.

Screening of small-molecule drugs. The upregulated and downregulated DEGs were mapped onto the connectivity map (CMAP) database to obtain the small-molecule drugs targeting the selected DEGs with the criterion of correlation score $>0.8$ (21). Thereafter, combined with the PPI information, an integrated network between DEGs and small molecular drugs was constructed, which was visualized using the Cytoscape software (version 3.2.1, http://cytoscape.org/) (22).

\section{Results}

Screened DEGs between ALL samples and control samples. Following the preprocessing and normalization for gene expression profile data, the medians of the ALL samples were similar (Fig. 1), indicating the validity of these results for the subsequent analysis. Based on the aforementioned criteria, a set of 116 genes was identified as DEGs consisting of 56 downregulated and 60 upregulated genes.

Clustering analysis of the DEGs. Using the pheatmap package of $\mathrm{R}$ language, the cluster heat map of the DEG expression was presented in Fig. 2. By performing biclustering analysis, it was identified that gene expression in pediatric ALL samples and control samples were distinct from each other suggesting that the DEGs that were selected were significant and reliable for distinguishing diseased and control samples.

Altered functions of the DEGs. The upregulated and downregulated DEGs were imported to the DAVID database to perform functional enrichment analysis. Accordingly, upregulated DEGs were established to be significantly enriched in GO functionality, including 'mesenchymal cell differentiation', 'mesenchymal cell' and 'mesenchymal development' The upregulated DEGs included bone marrow morphogenetic protein $2(B M P 2)$, semaphoring $3 \mathrm{~F}(S E M A 3 F)$ and ephrin $\mathrm{B} 1$ (EFNB1) (Table I). By contrast, the downregulated DEGs were associated with the terms 'cell cycle phase', 'cell cycle process' and 'cell cycle'. The downregulated genes included marker of proliferation Ki-67 (MIK67), cyclin F (CCNF) and nucleolar and spindle associated protein (NUSAPI) (Table II).

Integrated network between small-molecule drugs and targeted DEGs. Following the mapping of DEGs into the 


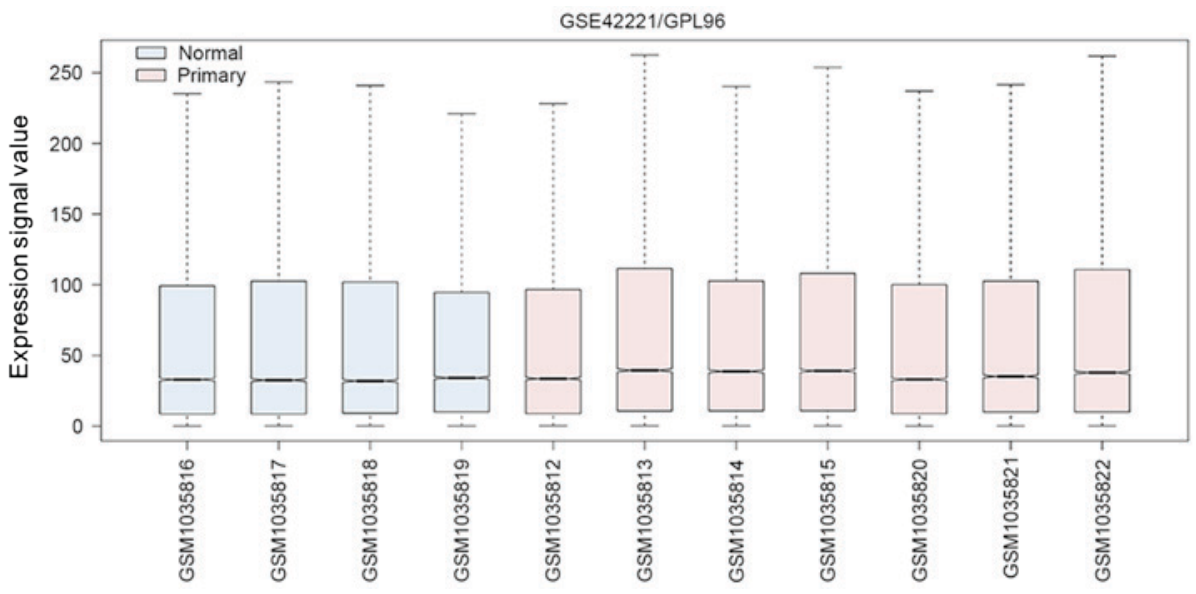

Figure 1. Box diagram of normalization of samples included in the current study. Blue boxes represent normal samples, and pink boxes represent ALL samples (primary). The middle black line represents the median of expression value of each sample. ALL, acute lymphoblastic leukemia; GSE, Gene Expression Omnibus DataSet; GPL, Gene Expression Omnibus platform; GSM, Gene Expression Omnibus.

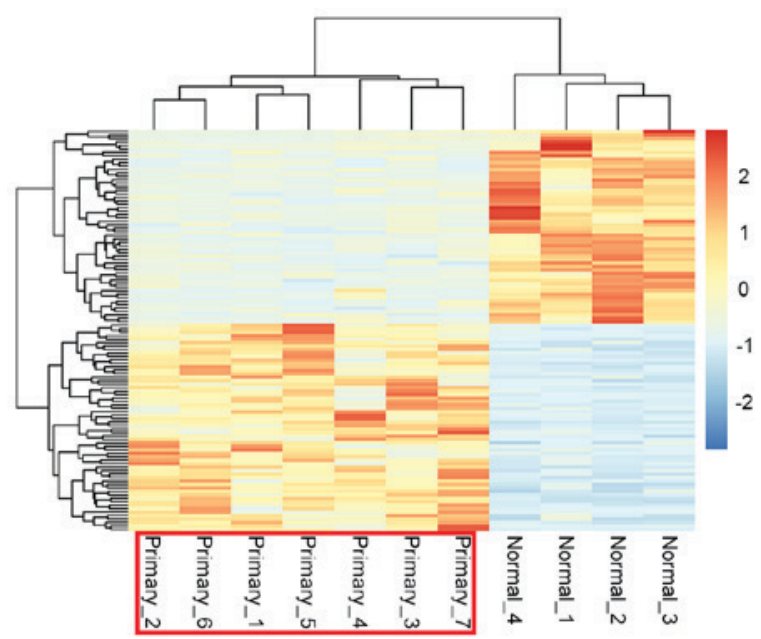

Figure 2. Heat map of clustering analysis of differentially expressed genes. The color change from blue to orange represents the expression value change from downregulation (blue) to upregulation (red). The sample numbers are presented below, including 7 disease samples (primary) and 4 normal samples.

String database, a subset of 169 PPIs were identified. In addition, the upregulated and downregulated genes were mapped onto the CMAP database to identify a list of small-molecule drugs that meet the predefined criterion (Table III). Quinostatin and carbimazole achieved high enrichment scores of 0.904 and -0.859 , respectively. These findings suggest that theses drugs were associated with ALL and may be potentially effective for the treatment of pediatric ALL.

Combining the PPIs with the DEGs and small-molecule drugs, an integrated network was constructed between associated DEGs and the small-molecule drugs (carbimazole and quinostatin) and associated DEGs (Fig. 3). In this integrated network, the target genes of carbimazole and quinostatin were predicted, including signal transducer and activator of transcription 3 (STAT3), nucleolar and spindle associated protein 1 (NUSAPI) and cell division cycle 20 $(C D C 20)$.

\section{Discussion}

In the present study, 116 DEGs were identified in pediatric ALL based on gene expression profile data, including 56 downregulated and 60 upregulated genes. Functional enrichment analysis demonstrated that upregulated DEGs, including $B M P 2, S E M A 3 F$ and $E F N B 1$, were significantly associated with mesenchymal cell differentiation and development processes, whilst downregulated DEGs, including MKI67, $C C N F$ and NUSAPl, were enriched for cell cycle processes.

In a previous study, mesenchymal cells were demonstrated to regulate the response of ALL cells to asparaginase, which is a major component of ALL therapy (23). Additionally, the differentially methylated genes between the two leukemia subgroups (CEBPA $A^{\text {sil }}$ and normal $\mathrm{CD} 34^{+}$bone marrow cells) were also associated with the GO term mesenchymal cell development (24), suggesting that mesenchymal cell differentiation and development may have important roles in regulating ALL. BMP2 was reported to be associated with the cardiac cushion epithelial-mesenchymal transition and the initiation of chondrogenic lineage development of mesenchymal stem cells $(25,26)$. In T-cell ALL, BMP2 was established to be an important regulator by acting upstream of the NOTCH1 signaling pathway (27). The SEMA3F encoded protein is primarily involved in signaling transduction. It has also been demonstrated that $S E M A 3 F$ is expressed in T-cell ALL, and it also functions in T-cell ALL (28). EFNB1 is another gene expressed in pediatric T-cell ALL (29). Although T-cell and B-cell leukomonocytes mature in the thymus and bone marrow, respectively, immune responses are implicated in both T-cell and B-cell ALL $(30,31)$. Therefore, the regulation of these genes in B-cell ALL may be similar with the gene regulation in T-cell ALL. Considering that the 3 upregulated genes in ALL samples were significantly enriched in the mesenchymal development process, it may be inferred that these genes are involved in the mesenchymal development process during pediatric B-cell ALL progression.

However, the downregulated genes, including MKI67, NUSAPI and CCNF, were significantly associated with the cell cycle. Cell cycle (including G0/G1 arrest) is a process, 
Table I. Significantly enriched Gene Ontology terms of upregulated genes.

\begin{tabular}{llll}
\hline Gene ontology term & Count & P-value & Genes \\
\hline 0048762 mesenchymal cell differentiation & 3 & $1.35 \times 10^{-2}$ & BMP2, SEMA3F, EFNB1 \\
0014031 mesenchymal cell development & 3 & $1.35 \times 10^{-2}$ & $B M P 2, S E M A 3 F, E F N B 1$ \\
0060485 mesenchyme development & 3 & $1.40 \times 10^{-2}$ & $B M P 2, S E M A 3 F, E F N B 1$ \\
0045765 regulation of angiogenesis & 3 & $2.02 \times 10^{-2}$ & $H H E X, N P R 1, E P H B 4$ \\
0000902 cell morphogenesis & 5 & $3.46 \times 10^{-2}$ & $B M P 2, L S T 1, E F N B 1, L 1 C A M, P O U 4 F 1$ \\
0006469 negative regulation of protein kinase activity & 3 & $3.67 \times 10^{-2}$ & $S H 3 B P 5, S P R Y 1, D U S P 6$ \\
0033673 negative regulation of kinase activity & 3 & $3.90 \times 10^{-2}$ & $S H 3 B P 5, S P R Y 1, D U S P 6$ \\
0051348 negative regulation of transferase activity & 3 & $4.38 \times 10^{-2}$ & $S H 3 B P 5, S P R Y 1, D U S P 6$ \\
$0032989 \sim$ cellular component morphogenesis & 5 & $4.84 \times 10^{-2}$ & $B M P 2, L S T 1, E F N B 1, L 1 C A M, P O U 4 F 1$
\end{tabular}

Count, number of genes enriched in the term.

Table II. Significantly enriched Gene Ontology terms of downregulated genes.

\begin{tabular}{|c|c|c|c|}
\hline Gene ontology term & Count & P-value & Genes \\
\hline 0022403 cell cycle phase & 17 & $1.31 \times 10^{-10}$ & $\begin{array}{l}C C N F, M K I 67, C E N P E, N U S A P 1, \\
C D C 20\end{array}$ \\
\hline 0022402 cell cycle process & 18 & $1.06 \times 10^{-9}$ & $\begin{array}{l}\text { MKI67, CCNF, NUSAP1, ESPL1, } \\
\text { CENPE }\end{array}$ \\
\hline 0007049 cell cycle & 20 & $1.18 \times 10^{-9}$ & $\begin{array}{l}\text { MKI67, CCNF, NUSAP1, CDC } 20, \\
\text { CENPE }\end{array}$ \\
\hline 0000279 M phase & 15 & $1.78 \times 10^{-9}$ & $\begin{array}{l}\text { KIF } 11, \text { MKI67, CCNF, NUSAP1, } \\
\text { CDC } 20\end{array}$ \\
\hline 0000280 nuclear division & 13 & $5.26 \times 10^{-9}$ & $\begin{array}{l}\text { KIF } 11, C C N F, \text { NUSAP1, CENPE, } \\
C D C 20\end{array}$ \\
\hline 0007067 mitosis & 13 & $5.26 \times 10^{-9}$ & $\begin{array}{l}\text { KIF 11, CCNF, NUSAP1, CENPE, } \\
\text { CDC } 20\end{array}$ \\
\hline 0000087 M phase of mitotic cell cycle & 13 & $6.51 \times 10^{-9}$ & $\begin{array}{l}\text { KIF 11, CCNF, NUSAP1, CENPE, } \\
C D C 20\end{array}$ \\
\hline 0048285 organelle fission & 13 & $8.44 \times 10^{-9}$ & $\begin{array}{l}\text { KIF 11, CCNF, NUSAP1, CENPE, } \\
\text { CDC } 20\end{array}$ \\
\hline 0000278 mitotic cell cycle & 15 & $8.72 \times 10^{-9}$ & $\begin{array}{l}\text { KIF } 11, C C N F, N U S A P 1, C D C 20, \\
\text { CENPE }\end{array}$ \\
\hline 0051301 cell division & 13 & $1.63 \times 10^{-7}$ & $\begin{array}{l}\text { KIF 11, CCNF, NUSAP1, CENPE, } \\
\text { CDC } 20\end{array}$ \\
\hline 0007059 chromosome segregation & 6 & $9.05 \times 10^{-3}$ & $\begin{array}{l}\text { SPC 25, NUSAP1, BIRC5, CENPE, } \\
\text { ESPL1, PTTG1 }\end{array}$ \\
\hline 0000226 microtubule cytoskeleton organization & 7 & $1.16 \times 10^{-2}$ & $\begin{array}{l}\text { SPC25, CAV1, KIF11, NUSAP1, ESPL1, } \\
\text { UBE2C, TACC3 }\end{array}$ \\
\hline 0007051 spindle organization & 5 & $2.05 \times 10^{-2}$ & SPC 25, KIF 11, ESPL1, UBE2C, TACC3 \\
\hline 0007017 microtubule-based process & 8 & $2.43 \times 10^{-2}$ & $\begin{array}{l}\text { SPC25, CAV1, KIF 11, NUSAP1, } \\
\text { CENPE, ESPL1, UBE2C, TACC3 }\end{array}$ \\
\hline
\end{tabular}

Count, number of genes enriched in the term.

which is typically dysregulated in ALL, (32). ALL is a result of the clonal expansion of hematopoietic progenitors that have undergone malignant transformation at distinct stages of differentiation (33). The B-cell lineage ALL is derived from
B cell precursors. The Ikaros-mediated cell cycle was determined as the endpoint in the tumor suppression pathway that was modulated by the pre-B cell receptor (34). Aberrations of genes that are involved in cell cycle control, including the 
Table III. Small molecular drugs significantly associated with differentially expressed genes.

\begin{tabular}{lcc}
\hline Cmap name & Enrichment score & P-value \\
\hline Carbimazole & -0.859 & 0.00561 \\
Nadolol & -0.854 & 0.00084 \\
Prestwick-691 & -0.845 & 0.00741 \\
Trihexyphenidyl & -0.829 & 0.01002 \\
Pargyline & 0.833 & 0.00115 \\
Blebbistatin & 0.858 & 0.04094 \\
Quinostatin & 0.904 & 0.01889 \\
\hline
\end{tabular}

Cmap, connectivity map.

cytokine receptor-like factor 2 gene, have been implicated in the progression and relapse of B-cell ALL (35). The majority of cell cycle genes were deregulated in the Bruton tyrosine kinase $(B T K)^{C 48 I S}$ mantle cell lymphoma (MCL) cells, especially the expression of MKI67 was remarkably decreased in the bone marrow at the point of relapse (36). A previous study demonstrated that microRNA-519d is a tumor suppressor that targets MKI67 in the hepatocellular carcinoma cell line (37), which may account for the downregulation of MKI67. NUSAP1 is a protein that is key for spindle movement (38). MRD is considered to be an important predictor of relapse in ALL (39), and reduced expression of NUSAPI was identified in patients with MRD (40), which is consistent with the finding of downregulated NUSAPI in the current study. $C C N F$ encodes a member of the cyclin family that serves important roles in cell cycle transitions (41). The downregulation of $C C N F$ was also established in B-cell ALL (42). NUSAP1 and $C C N F$ were associated with altered cell cycle in acute myeloid leukemia (43), therefore providing further evidence of the role of the two genes in cell cycle modulation. These results collectively suggest that the 3 genes (MKI67, NUSAP1 and CCNF) mediate cell cycle processes and may have regulatory roles in the B-cell ALL progression.

The present study also identified a number of important small molecule drugs, including quinostatin and carbimazole. NOTCH1 is a member of the Notch family that has vital roles in a number of cellular processes. The activation of NOTCH1 signaling promotes important functions in the pathogenesis of T-cell ALL (44). NOTCH1 inhibits cell apoptosis via the transcriptional suppressor, hairy and enhancer of split 1 (HES1)-mediated repression downstream of NOTCH signaling in T-cell ALL (45). The small molecule perhexiline was identified as a HES1 modulator drug with potent anti-leukemic effects (45). Notably based on the information in CMAP, quinostatin was identified as another important small molecule drug that may target HES1 with a high enrichment score (0.983) (45), suggesting a potential inhibitory role of quinostatin in ALL. Additionally, quinostatin was reported to potently inhibit the mammalian target of rapamycin signaling network by directly targeting lipid-kinase activity (46). Combining these findings with the results of the present study that quinostatin was associated with DEGs (enrichment score, 0.904), quinostatin may be a potential therapeutic drug for

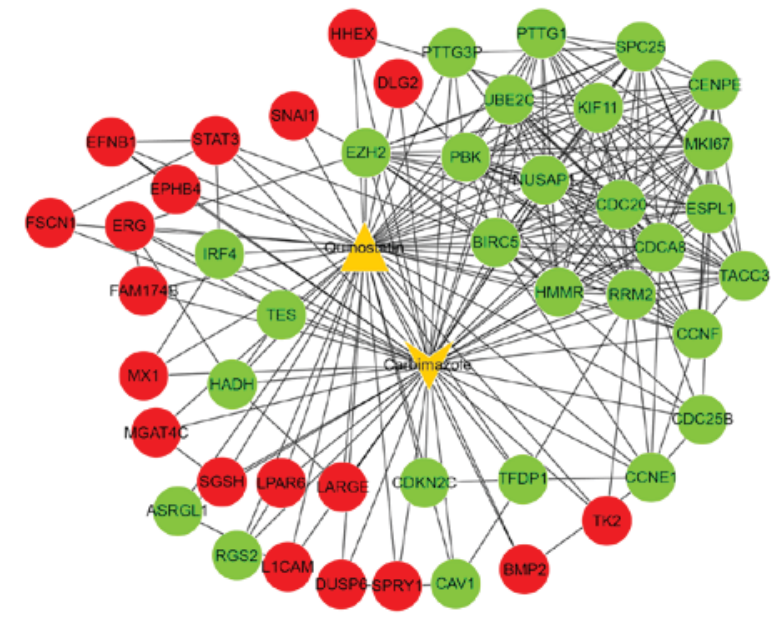

Figure 3. The integrated network between the two small-molecule drugs (quinostatin and carbimazole) and differentially expressed genes. Red spots indicate significantly upregulated genes and green spots indicate downregulated genes. Orange triangles represent the small-molecule drugs.

treating ALL. However, further experimental validations are required to confirm this prediction.

Carbimazole has been widely used in the treatment of ALL $(47,48)$. In the present study, it was demonstrated that quinostatin and carbimazole share a number of common target genes, including STAT3, NUSAP1 and CDC20. Excluding the aforementioned functions, STAT3 was revealed to mediate an oncogenic association with two characterized transcription factors, Ets-related protein Tel1 (TEL) and Runt related transcription factor $1(A M L 1)$, in $\mathrm{t}(12 ; 21)$ translocation, which has been reported to be the most frequent chromosomal abnormality in pediatric leukemia (49). NUSAP is an important mitotic regulator, and the activity of NUSAP is vital for a number of cellular processes during mitosis (50). CDC20, as a mitotic complex/cyclosome activator, directly interacts with anaphase-promoting complex, which leads to the promotion of onset of anaphase and mitotic exit via the ubiquitination of securin and cyclin B1 $(51,52)$. Taken together, it may be hypothesized that the two small molecule drugs, particularly quinostatin, may be an effective agent for the management of ALL, as it targets STAT3, NUSAP1 and CDC2O genes. However, further experiments are required to validate these targets. Although the current study performed a comprehensive bioinformatics analysis, it should be noted that the data were derived from a previously published study with a small sample size, and the present study did not consider the subgroups of ALL. All the conclusions of the current study require further experimental validation.

In conclusion, by using a bioinformatic methodology, the current study identified that the dysregulated biological processes (including mesenchymal cell differentiation and development) that were mediated by the upregulated genes and the cell cycle processes that were mediated by downregulated genes may have significant roles in the pathogenesis and prognosis of pediatric B-cell ALL. In addition, quinostatin may be a potent novel agent for the management of pediatric B-cell ALL as it targets a large number of DEGs, including STAT3, NUSAP1 and CDC2O. However, the results obtained in the present study require further validation. 


\section{References}

1. Krajinovic M, Lamothe S, Labuda D, Lemieux-Blanchard E, Theoret Y, Moghrabi A and Sinnett D: Role of MTHFR genetic polymorphisms in the susceptibility to childhood acute lymphoblastic leukemia. Blood 103: 252-257, 2004.

2. Howlader N, Noone A, Krapcho M, et al: SEER Cancer Statistics Review, 1975-2011. Bethesda, MD: National Cancer Institute. Journal, 2014.

3. Barrington-Trimis JL, Cockburn M, Metayer C, Gauderman WJ, Wiemels J and McKean-Cowdin R: Rising rates of acute lymphoblastic leukemia in Hispanic children: Trends in incidence from 1992 to 2011. Blood 125: 3033-3034, 2015.

4. Martelli MF, Di Ianni M, Ruggeri L, Falzetti F, Carotti A, Terenzi A, Pierini A, Massei MS, Amico L, Urbani E, et al: HLA-haploidentical transplantation with regulatory and conventional T-cell adoptive immunotherapy prevents acute leukemia relapse. Blood 124: 638-644, 2014

5. Coustan-Smith E, Song G, Clark C, Key L, Liu P, Mehrpooya M, Stow P, Su X, Shurtleff S, Pui CH, et al: New markers for minimal residual disease detection in acute lymphoblastic leukemia. Blood 117: 6267-6276, 2011.

6. Ross ME, Zhou X, Song G, Shurtleff SA, Girtman K, Williams WK, Liu HC, Mahfouz R, Raimondi SC, Lenny N, et al: Classification of pediatric acute lymphoblastic leukemia by gene expression profiling. Blood 102: 2951-2959, 2003.

7. Cario G, Stanulla M, Fine BM, Teuffel O, Neuhoff NV, Schrauder A, Flohr T, Schäfer BW, Bartram CR, Welte K, et al: Distinct gene expression profiles determine molecular treatment response in childhood acute lymphoblastic leukemia. Blood 105 821-826, 2005.

8. Chen JS, Coustan-Smith E, Suzuki T, Neale GA, Mihara K, Pui $\mathrm{CH}$ and Campana D: Identification of novel markers for monitoring minimal residual disease in acute lymphoblastic leukemia. Blood 97: 2115-2120, 2001.

9. Wei MC and Cleary ML: Novel methods and approaches to acute lymphoblastic leukemia drug discovery. Expert Opin Drug Discov 9: 1435-1446, 2014.

10. Habibi D, Ogloff N, Jalili RB, Yost A, Weng AP, Ghahary A and Ong CJ: Borrelidin, a small molecule nitrile-containing macrolide inhibitor of threonyl-tRNA synthetase, is a potent inducer of apoptosis in acute lymphoblastic leukemia. Invest New Drugs 30: 1361-1370, 2012.

11. Harder L, Eschenburg G, Zech A, Kriebitzsch N, Otto B, Streichert T, Behlich AS, Dierck K, Klingler B, Hansen A, et al: Aberrant ZNF423 impedes B cell differentiation and is linked to adverse outcome of ETV6-RUNX1 negative B precursor acute lymphoblastic leukemia. J Exp Med 210: 2289-2304, 2013.

12. Harder L, Otto B and Horstmann MA: Transcriptional dysregulation of the multifunctional zinc finger factor 423 in acute lymphoblastic leukemia of childhood. Genomics Data 2: 96-98, 2014.

13. Fujita A, Sato JR, Rodrigues Lde O, Ferreira CE and Sogayar MC: Evaluating different methods of microarray data normalization. BMC Bioinformatics 7: 469, 2006.

14. Smyth GK: Limma: Linear models for microarray data. In: Bioinformatics and computational biology solutions using R and Bioconductor. Springer, pp397-pp420, 2005.

15. Benjamini Y and Hochberg Y: Controlling the false discovery rate: A practical and powerful approach to multiple testing. J Royal Statistical Soc Series B (Methodological) 57: 289-300, 1995.

16. Szekely GJ and Rizzo ML: Hierarchical clustering via joint between-within distances: Extending Ward's minimum variance method. J Classification 22: 151-183, 2005.

17. Press WH, Teukolsky SA, Vetterling WT and Flannery BP: Hierarchical Clustering by Phylogenetic Trees. Section 16.4. In: Numerical Recipes: The Art of Scientific Computing. 3rd edition. Cambridge University Press, New York, NY, 2007.

18. Deza MM and Deza E: Encyclopedia of distances. Springer, Heidelberg, pp1-583, 2009.

19. Dennis G Jr, Sherman BT, Hosack DA, Yang J, Gao W, Lane HC and Lempicki RA: DAVID: Database for annotation, visualization, and integrated discovery. Genome Biol 4: P3, 2003.

20. Szklarczyk D, Franceschini A, Kuhn M, Simonovic M, Roth A Minguez P, Doerks T, Stark M, Muller J, Bork P, et al: The STRING database in 2011: Functional interaction networks of proteins, globally integrated and scored. Nucleic Acids Res 39 (Database issue): D561-D568, 2011.
21. Evan GI and Vousden KH: Proliferation, cell cycle and apoptosis in cancer. Nature 411: 342-348, 2001.

22. Kohl M, Wiese S and Warscheid B: Cytoscape: Software for visualization and analysis of biological networks. In: Data Mining in Proteomics. Springer, pp291-pp303, 2011.

23. Iwamoto S, Mihara K, Downing JR, Pui CH and Campana D: Mesenchymal cells regulate the response of acute lymphoblastic leukemia cells to asparaginase. J Clin Invest 117: 1049-1057, 2007.

24. Figueroa ME, Wouters BJ, Skrabanek L, Glass J, Li Y, Erpelinck-Verschueren CA, Langerak AW, Löwenberg B, Fazzari M, Greally JM, et al: Genome wide epigenetic analysis delineates a biologically distinct immature acute leukemia with myeloid/T-lymphoid features. Blood 113: 2795-27804, 2009.

25. Ma L, Lu MF, Schwartz RJ and Martin JF: Bmp2 is essential for cardiac cushion epithelial-mesenchymal transition and myocardial patterning. Development 132: 5601-5611, 2005.

26. Schmitt B, Ringe J, Häupl T, Notter M, Manz R, Burmester GR, Sittinger M and Kaps C: BMP2 initiates chondrogenic lineage development of adult human mesenchymal stem cells in high-density culture. Differentiation 71: 567-577, 2003.

27. Chiaramonte R, Basile A, Tassi E, Calzavara E, Cecchinato V, Rossi V, Biondi A and Comi P: A wide role for NOTCH1 signaling in acute leukemia. Cancer Lett 219: 113-120, 2005.

28. Mendes-da-Cruz DA, Brignier AC, Asnafi V, Baleydier F, Messias CV, Lepelletier Y, Bedjaoui N, Renand A, Smaniotto S, Canioni D, et al: Semaphorin $3 \mathrm{~F}$ and Neuropilin-2 control the migration of human T-cell precursors. PLoS One 9: e103405, 2014

29. Jiang G, Freywald T, Webster J, Kozan D, Geyer R, DeCoteau J, Narendran A and Freywald A: In human leukemia cells ephrin-B-induced invasive activity is supported by lck and is associated with reassembling of lipid raft signaling complexes. Mol Cancer Res 6: 291-305, 2008.

30. O'Brien MM, Lee-Kim Y, George TI, McClain KL, Twist CJ and Jeng M: Precursor B-cell acute lymphoblastic leukemia presenting with hemophagocytic lymphohistiocytosis. Pediatr Blood Cancer 50: 381-383, 2008.

31. Medyouf H, Alcalde H, Berthier C, Guillemin MC, dos Santos NR, Janin A, Decaudin D, de Thé H and Ghysdael J: Targeting calcineurin activation as a therapeutic strategy for T-cell acute lymphoblastic leukemia. Nat Med 13: 736-741, 2007.

32. Weng AP, Ferrando AA, Lee W, Morris JP III, Silverman LB, Sanchez-Irizarry C, Blacklow SC, Look AT and Aster JC: Activating mutations of NOTCH1 in human T cell acute lymphoblastic leukemia. Science 306: 269-271, 2004

33. Barata JT, Cardoso AA, Nadler LM and Boussiotis VA: Interleukin-7 promotes survival and cell cycle progression of T-cell acute lymphoblastic leukemia cells by down-regulating the cyclin-dependent kinase inhibitor p27(kip1). Blood 98: $1524-1531,2001$

34. Trageser D, Iacobucci I, Nahar R, Duy C, von Levetzow G, Klemm L, Park E, Schuh W, Gruber T, Herzog S, et al: Pre-B cell receptor-mediated cell cycle arrest in Philadelphia chromosome-positive acute lymphoblastic leukemia requires IKAROS function. J Exp Med 206: 1739-1753, 2009.

35. Russell LJ, Capasso M, Vater I, Akasaka T, Bernard OA, Calasanz MJ, Chandrasekaran T, Chapiro E, Gesk S, Griffiths M, et al: Deregulated expression of cytokine receptor gene, CRLF2, is involved in lymphoid transformation in B-cell precursor acute lymphoblastic leukemia. Blood 114: 2688-2698, 2009.

36. Chiron D, Di Liberto M, Martin P, Huang X, Sharman J, Blecua P, Mathew S, Vijay P, Eng K, Ali S, et al: Cell-cycle reprogramming for PI3K inhibition overrides a relapse-specific C481S BTK mutation revealed by longitudinal functional genomics in mantle cell lymphoma. Cancer Discov 4: 1022-1035, 2014

37. Hou YY, Cao WW, Li L, Li SP, Liu T, Wan HY, Liu M, Li X and Tang H: MicroRNA-519d targets MKi67 and suppresses cell growth in the hepatocellular carcinoma cell line QGY-7703. Cancer Lett 307: 182-190, 2011

38. Vanden Bosch A, Raemaekers T, Denayer S, Torrekens S, Smets N, Moermans K, Dewerchin M, Carmeliet P and Carmeliet G: NuSAP is essential for chromatin-induced spindle formation during early embryogenesis. J Cell Sci 123: 3244-3255, 2010.

39. Borowitz MJ, Devidas M, Hunger SP, Bowman WP, Carroll AJ, Carroll WL, Linda S, Martin PL, Pullen DJ, Viswanatha D, et al: Clinical significance of minimal residual disease in childhood acute lymphoblastic leukemia and its relationship to other prognostic factors: A Children's Oncology Group study. Blood 111: 5477-5485, 2008 . 
40. Campana D: Molecular determinants of treatment response in acute lymphoblastic leukemia. Hematology Am Soc Hematol Educ Program: 366-373, 2008.

41. Tetzlaff MT, Bai C, Finegold M, Wilson J, Harper JW, Mahon KA and Elledge SJ: Cyclin F disruption compromises placental development and affects normal cell cycle execution. Mol Cell Biol 24: 2487-2498, 2004.

42. Bhadri VA, Cowley MJ, Kaplan W, Trahair TN and Lock RB: Evaluation of the NOD/SCID xenograft model for glucocorticoid-regulated gene expression in childhood B-cell precursor acute lymphoblastic leukemia. BMC Genomics 12: 565, 2011.

43. Hatfield KJ, Reikvam $H$ and Bruserud $\varnothing$ : Identification of a subset of patients with acute myeloid leukemia characterized by long-term in vitro proliferation and altered cell cycle regulation of the leukemic cells. Expert Opin Ther Targets 18: 1237-1251, 2014.

44. Paganin M and Ferrando A: Molecular pathogenesis and targeted therapies for NOTCH1-induced T-cell acute lymphoblastic leukemia. Blood Rev 25: 83-90, 2011.

45. Schnell SA, Ambesi-Impiombato A, Sanchez-Martin M, Belver L, Xu L, Qin Y, Kageyama R and Ferrando AA: Therapeutic targeting of HES1 transcriptional programs in T-ALL. Blood 125: 2806-2814, 2015.

46. Yang J, Shamji A, Matchacheep S and Schreiber SL: Identification of a small-molecule inhibitor of class Ia PI3Ks with cell-based screening. Chem Biol 14: 371-377, 2007.
47. Au W, Lie A, Kung A, Liang R, Hawkins B and Kwong Y: Autoimmune thyroid dysfunction after hematopoietic stem cell transplantation. Bone Marrow Transplant 35: 383-388, 2005.

48. Tatevossian R, Blair JC, Plowman PN, Savage MO and Shankar AG: Thyrotoxicosis after matched unrelated bone marrow transplantation. J Pediatr Hematol Oncol 26: 529-531, 2004.

49. Mangolini M, de Boer J, Walf-Vorderwülbecke V, Pieters R, den Boer ML and Williams O: STAT3 mediates oncogenic addiction to TEL-AML1 in $\mathrm{t}(12 ; 21)$ acute lymphoblastic leukemia. Blood 122: 542-549, 2013.

50. Iyer J, Moghe S, Furukawa M and Tsai MY: What's Nu(SAP) in mitosis and cancer? Cell Signal 23: 991-998, 2011.

51. Tian W, Li B, Warrington R, Tomchick DR, Yu H and Luo X: Structural analysis of human Cdc20 supports multisite degron recognition by APC/C. Proc Natl Acad Sci USA 109: 18419-18424, 2012.

52. Battula VL, Chen Y, Cabreira Mda G, Ruvolo V, Wang Z, Ma W, Konoplev S, Shpall E, Lyons K, Strunk D, et al: Connective tissue grow th factor regulates adipocyte differentiation of mesenchymal stromal cells and facilitates leukemia bone marrow engraftment. Blood 122: 357-366, 2013. 